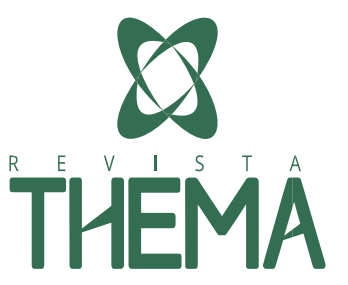

\title{
Altas diluições dinamizadas de nitrato de cálcio e sulfato de potássio no manejo de tripes, míldio e rendimento de cebola em sistema orgânico de produção
}

\author{
High dilutions dinamized of calcium nitrate and potassium \\ sulphate on the management of thrips, downy mildew and onion \\ yield under organic system
}

Paulo Antonio de Souza Gonçalves ${ }^{1}$; Pedro Boff ${ }^{1}$; Edivânio Rodrigues de Araújo ${ }^{1}$

\section{RESUMO}

Estudos com substâncias ultradiluídas também têm sido realizados como estratégia de manejo fitossanitário para sistemas orgânicos de produção. O objetivo deste trabalho foi avaliar o efeito de altas diluições dinamizadas de nitrato de cálcio e sulfato de potássio sobre a incidência e danos do tripes Thrips tabaci, severidade do mildio Peronospora destructor e rendimento de cebola em sistema de produção orgânico. 0 estudo foi conduzido na Estação Experimental de Ituporanga/Epagri, SC, em dois experimentos distintos durante três anos para altas diluições de sulfato de potássio, entre 2011 a 2013, e para nitrato de cálcio, entre 2013 a 2015. Os tratamentos foram altas diluições de nitrato de cálcio e sulfato de potássio em pulverizações foliares nas diluições 6,12 e $30 \mathrm{CH}$ ( $\mathrm{CH}$, escala de diluição centesimal hahnemanniana), além de testemunha sem aplicação. $\mathrm{O}$ delineamento experimental foi casualizado em blocos com quatro repetições. A incidência e danos de tripes, índice de clorofila, severidade de míldio e rendimento de cebola não foram influenciados pelos tratamentos.

Palavras-chave: Allium cepa; Thrips tabaci; Peronospora destructor; homeopatia, agroecologia.

\begin{abstract}
Assays with substances in high dilutions have also been used as phytosanitary management strategy for organic production systems. The objective of this study was to evaluate the effect of high dilutions of calcium nitrate and potassium sulfate on the incidence and damage of thrips, Thrips tabaci; downy mildew severity, Peronospora destructor; and yield of organic onion. The study was conducted in two different experiments during three years for high dilutions of potassium sulphate (2011-2013), and calcium nitrate (2013-2015), at Epagri, Experimental Station of Ituporanga, Santa Catarina state. The treatments were high dilutions, 6, 12 and $30 \mathrm{CH}(\mathrm{CH}$, hahnemannian centesimal scale) of calcium nitrate and potassium sulphate applied by foliar sprays, besides control without application. Randomized blocks design with four replications was used. The incidence and damage of thrips, chlorophyll index, downy mildew severity, and onion yield were not affected by treatments.
\end{abstract}

Keywords: Allium cepa; Thrips tabaci; Peronospora destructor; homeopathy; agroecology.

\footnotetext{
${ }^{1}$ Epagri - Estação Experimental de Ituporanga, Ituporanga/SC - Brasil
} 


\section{INTRODUÇÃO}

A cebola é a principal hortaliça de retorno econômicos em Santa Catarina, registrando a maior produção nacional, com volume de 426.916 t, em uma área plantada de 21.398 ha na safra de 2015, com produtividade média de 21,1 t.ha-1 (IBGE, 2016). A Epagri, Empresa de Pesquisa Agropecuária e Extensão Rural de Santa Catarina, desenvolve pesquisas para reduzir e principalmente abolir o uso de agrotóxicos na cultura da cebola com a finalidade de produzir um alimento seguro ao consumidor.

O tripes, Thrips tabaci Lindeman 1888 (Thysanoptera: Thripidae) é o inseto que pode atingir níveis de praga na cultura da cebola, mesmo em outras regiões do Brasil (GONÇALVES, 2016). Altas densidades populacionais de tripes em cebola danificam as plantas pela sucção de seiva foliar, que causam lesões esbranquiçadas, retorcimento e seca de ponteiros das folhas, e diminuição de massa dos bulbos com perdas em produtividade e na pós-colheita (GONÇALVES, 2016).

O míldio da cebola, causado pelo fungo oomiceto Peronospora destructor (Berkeley) Caspary ex Berkeley, é a principal doença parasitaria da cultura em regiões onde predominam temperaturas mais amenas associadas com a alta umidade. O controle químico tem sido a principal forma de manejo da doença em sistema convencional (MARCUZZO \& ARAÚJO, 2016). Logo, a busca por métodos alternativos de controle se faz necessária, uma vez que a demanda por alimentos e ambiente saudáveis vem aumentando e a sociedade é crítica do modo como os alimentos são produzidos.

A produção de cebola em sistemas orgânicos tem sido apoiada pela Epagri em escala familiar (GONÇALVES \& WAMSER, 2007). Substâncias em altas diluições dinamizadas são adequadas para o manejo fitossanitário na produção orgânica de alimentos (CARNEIRO et al., 2011). No Brasil a legislação para a produção orgânica em agropecuária permite o uso de altas diluições dinamizadas em sistemas ecológicos de produção (MINISTÉRIO DA AGRICULTURA, 2011).

Substâncias em altas diluições pesquisadas em cebola apresentaram potencial de manejo fitossanitário, incremento de produtividade, melhoria da composição mineral de bulbos e rendimento pós-colheita. A incidência de tripes foi reduzida por Artemisia verlotorum 30CH (GONÇALVES et al., 2010), Natrum muriaticum 12CH (GONÇALVES et al., 2011), e calcário de conchas 6CH (GONÇALVES et al., 2014). A incidência e severidade de míldio foram reduzidas por nitrato de cálcio $6 \mathrm{CH}$ (GONÇALVES \& CARRÉ-MISSIO, 2011). Calcarea fluorica 30CH em cebolinha, Allium fistolosum, incrementou a massa foliar (LUIS \& MORENO, 2007). Calcário de conchas nas diluições 6cH e $12 \mathrm{CH}$ ( $\mathrm{CH}$, escala centesimal hahnemanniana) e Natrum muriaticum $12 \mathrm{CH}$ aumentaram a produtividade de cebola (GONÇALVES et al. 2009, 2011). Natrum muriaticum 12CH favoreceu a composição mineral de bulbos para os nutrientes P, Fe, Si e K (GONÇALVES et al., 2012). A conservação pós-colheita foi incrementada pelo uso de calcário de conchas $6 \mathrm{CH}$ associado a Natrum muriaticum $12 \mathrm{CH}$ (GONÇALVES et al., 2014).

O potássio, nitrogênio e cálcio são nutrientes exportados em altas quantidades por bulbos de cebola. O híbrido "Superex" exportou pelos bulbos (kg.ha-1): K $(80,3)$; N $(56,7)$ e Ca $(41,7)$ (PÔRTO el al., 2007). O cultivar de cebola "Alfa tropical" exportou pelos bulbos (kg.ha-1): N $(70,42) ; \mathrm{K}(57,39)$ e Ca $(25,09)$ (VIDIGAL et al., 2010). Em cebola convencional cultivada na Epagri, para os cultivares Crioula Alto Vale Epagri 362 e Empasc 352 Bola Precoce foi observada a seguinte ordem de composição destes nutrientes nos bulbos, N>K>Ca (GONÇALVES et al., 2012; MENEZES JúNIOR et al., 2013). 
O objetivo deste estudo foi avaliar altas diluições dinamizadas de nitrato de cálcio e sulfato de potássio sobre a incidência e danos de tripes, severidade de míldio, índice de clorofila e rendimento de cebola em sistema de produção orgânico.

\section{MATERIAIS E MÉTODOS}

Os estudos foram realizados a campo na Epagri, Estação Experimental de Ituporanga, SC, situada a $450 \mathrm{~m}$ de altitude nas coordenadas geográficas $27^{\circ} 22^{\prime} \mathrm{S}$ de latitude e $49{ }^{\circ} 35^{\prime} \mathrm{W}$ de longitude. $\mathrm{O}$ cultivar de cebola utilizada foi Epagri 362 Crioula Alto Vale. Os experimentos foram conduzidos, separadamente, para altas diluições de nitrato de cálcio e sulfato de potássio por três anos consecutivos. O transplante e a colheita foram realizados, respectivamente, no experimento com sulfato de potássio em 24/08/2011 e 05/12/2011; 31/08/2012 e 10/12/2012; 20/08/2013 e 06/12/2013; e para nitrato de cálcio em 20/08/2013 e 06/12/2013; 18/08/2014 e 02/12/2014; 20/08/2015 e 07/12/2015. O espaçamento utilizado foi de $40 \mathrm{~cm}$ entre linhas e de $10 \mathrm{~cm}$ entre plantas na linha. As parcelas experimentais foram compostas por duas linhas de $10 \mathrm{~m}$ e para determinação da área útil foram excluídas cinco plantas nas extremidades. $O$ transplantio foi realizado em sistema de plantio direto sobre palha de centeio e nabo forrageiro, com densidade de semeadura de 120 kg.ha-1 e $20 \mathrm{~kg}^{-h^{-1}}{ }^{-1}$, respectivamente, semeados em maio. Este consórcio de plantas de cobertura foi acamado com rolo-faca. Os sulcos foram abertos imediatamente antes do transplantio de mudas, utilizando um microtrator com enxadas de corte e disco adaptados para o sistema de plantio direto na palha. A adubação em 2011 foi realizada com 3 t.ha-1 de esterco de aves (EAV), e 1,3 t.ha ${ }^{-1}$ de fosfato natural (FN) de Gafsa com $9 \%$ de fósforo solúvel na base. No ano de 2012, foi utilizado 9 t.ha ${ }^{-1}$ de EAV, dividido em 3 doses iguais de 3 t.ha ${ }^{-1}$, sendo a primeira sobre as plantas de cobertura, a segunda no transplante e a última aos 34 dias após transplante (DAT), além de 0,6 t.ha-1 de FN na base. No ano de 2013 a adubação foi similar a de 2012, porém o parcelamento do EAV foi realizado em duas doses iguais de 4,5 t.ha-1 ${ }^{-1}$ a primeira na base e a segunda aos 51 DAT. Nos anos de 2014 e 2015 as adubações foram realizadas com 1,8 t.ha ${ }^{-1}$ de FN e 4,5 t.ha ${ }^{-1}$ de EAV na base e 4,5 t.ha-1 de EAV em cobertura, respectivamente, aos 30 e 32 DAT.

Os tratamentos foram altas diluições dinamizadas de nitrato de cálcio e sulfato de potássio em pulverizações foliares a 0,5\% nas 6, 12 e $30 \mathrm{CH}(\mathrm{CH}$, escala de diluição centesimal hahnemahniana) e testemunha sem aplicação. O delineamento experimental foi casualizado em blocos, com quatro repetições. As altas diluições dinamizadas foram preparadas no Laboratório de Homeopatia e Saúde Vegetal da Epagri, Estação Experimental de Lages, SC, de acordo com o estabelecido na FARMACOPÉIA HOMEOPÁTICA BRASILEIRA (2011).

A incidência de tripes foi avaliada um dia após as pulverizações em cinco plantas selecionadas ao acaso por parcela. A incidência de tripes foi aferida com auxílio de uma escala visual com notas de níveis de infestação, sendo 1= baixa; 3= média e 9= alta nos anos de 2011 a 2014. No ano de 2015 esta escala visual com notas foi ampliada com os seguintes níveis: (zero, ausência de ninfas), 1 (até seis ninfas), 3 (até 15 ninfas, considerado nível de dano econômico), 9 (população $\geq 20$ ninfas) (GONÇALVES et al., 2017). O nível de dano econômico para a incidência de tripes corresponde a nota 3 e superiores. A avaliação de incidência de tripes foi iniciada aos 64, 60, 50, 50 e 48 dias após transplante, respectivamente em 2011, 2012, 2013, 2014 e 2015. As pulverizações semanais foram aplicadas em número de seis em 2011 e sete em 2012, 2013, 2014 e 2015. Os danos de tripes foram determinados no início da maturação fisiológica das plantas com tombamento de plantas aos 91, 89, 
99, 99 e 96 DAT, respectivamente, em 2011, 2012, 2013, 2014 e 2015. Os danos de tripes foram avaliados com auxílio de uma escala visual com notas de diferentes níveis de lesões esbranquiçadas nas folhas, baixo $=1$, médio $=3$ e alto $=9$ (GONÇALVES et al., 2014).

No experimento com altas diluições de sulfato de potássio, a severidade de míldio foi quantificada pela determinação da porcentagem de folhas totalmente danificadas pela doença no final do ciclo da cultura, em cinco plantas escolhidas ao acaso por parcela aos 89 e 87 DAT, respectivamente em 2011 e 2012.

No experimento com nitrato de cálcio, a quantificação da severidade do míldio iniciou-se em 57 e 55 DAT, nos anos de 2014 e 2015, respectivamente. Em 2014, quinzenalmente, um total de quatro avaliações foram realizadas. Já em 2015, as avaliações foram semanais, totalizando seis. Utilizou-se a escala proposta por Mohibullah (1992), com adaptações, para atribuição de notas e consequente valor de severidade para as parcelas experimentais. Desta forma foi estabelecida a seguinte correlação nota/porcentagem de área foliar lesionada por míldio: $1 / 0 \%=$ sem sintomas; $2 / 1 \%=$ apenas algumas folhas atacadas; $3 / 5 \%=$ aproximadamente $25 \%$ do total de plantas da parcela atacadas; $4 / 10 \%=$ mais que $50 \%$ das plantas da parcela atacadas, ataque restrito a uma folha por planta; $5 / 20 \%=$ todas as plantas da parcela atacadas, ataque restrito a uma ou duas folhas por planta; $6 / 50 \%$ = todas as plantas da parcela atacadas, três a quatro folhas atacadas por planta, parcela ainda mantém uma boa coloração verde; $7 / 75 \%=$ todas as folhas atacadas, parcela apresenta um aspecto inicial de queima das folhas; $8 / 90 \%=$ todas as folhas severamente atacadas, coloração verde restrita à parte central da parcela e/ou das plantas; $9 / 100 \%=$ todas as folhas completamente queimadas. Os valores das notas de severidade e respectivas porcentagens de área foliar lesionada foram integralizados e calculados pela área abaixo da curva de progresso da doença - AACPD (SHANER \& FINNEY, 1977).

O índice de clorofila foi determinado com o uso de um clorofilômetro (Clorofilog-CFL1030 - Falker®), na porção central da primeira folha mais alta totalmente expandida, aos 83, 94 e 93 DAT, respectivamente nos anos de 2012, 2013 e 2014.

A produtividade foi determinada pela colheita ao acaso de 50 bulbos por linha, com um total de 100 bulbos por parcela. Na produtividade comercial, conforme as normas de mercado, foram considerados os bulbos com diâmetro superior a $5 \mathrm{~cm}$, que recebem maior valor para a venda pago pelo atacadista aos agricultores. A conservação pós-colheita de bulbos de cebola foi realizada pela armazenagem em caixas plásticas com capacidade de $22 \mathrm{~kg}$. Estas caixas foram depositadas em galpão de madeira similar ao adotado para armazenagem de cebola pelos agricultores da região do Alto vale do Itajaí, SC. Após cinco meses de armazenagem, foi determinado o rendimento pós-colheita pelo descarte de bulbos brotados e com podridão por bacterioses.

A análise de regressão foi utilizada para se verificar o ajuste dos tratamentos com as variáveis e realizada a análise de variância pelo programa $\mathrm{SAS}^{\circledR}$ ou Genes ${ }^{\circledR}$. 


\section{RESULTADOS E DISCUSSÕES}

No experimento com nitrato de cálcio a nota média de incidência $(1,9)$ e danos de tripes $(5,2)$ foi similar entre tratamentos (Tabela 1). Isto contrasta com o efeito da redução da incidência de tripes com calcário de conchas $6 \mathrm{CH}$ observado em estudo nas mesmas condições (GONÇALVES et al., 20114). Isto sugere que altas diluições de cálcio com origem natural, como o calcário de conchas, podem reduzir a incidência de tripes em cebola. Enquanto que o cálcio de origem sintética, nitrato de cálcio, não apresenta este efeito. O calcário de conchas com matéria prima equivalente à homeopatia Calcarea carbonica contribui para rigidez de tecido das plantas e consistência da epiderme (TICHAVSKÝ, 2009). Provavelmente, esta alteração nos tecidos foliares favoreça a diminuição da incidência de tripes.

No experimento com sulfato de potássio os valores médios de notas de incidência $(3,6)$, e danos de tripes $(5,4)$, também, não diferiram entre tratamentos (Tabela 2). Substância em alta diluição contendo potássio, equivalente a homeopatia Kali carbonicum, é indicada para manejo de insetos em geral, principalmente minadores (TICHAVSKÝ, 2009). Como o tripes ( $T$. tabaCl) que é um inseto sugador. Talvez este efeito não tenha sido constatado pela diferença no hábito alimentar.

Tabela 1. Notas da incidência (INC) e danos (DN) de Thrips tabacipor planta; área abaixo da curva de progresso da doença para nota de severidade (PDSEV) e para porcentagem de área foliar lesionada (PDAFL) do míldio, Peronospora destructor, índice de clorofila (CLOR); porcentagem de bulbos comerciais (PC); produtividade total (PT em t.ha ${ }^{-1}$ ); peso médio de bulbos (PB em g); porcentagem de rendimento pós-colheita (RPC) de cebola. Epagri, Ituporanga, SC, média das safras 2013, 2014 e 2015.

\begin{tabular}{|c|c|c|c|c|c|c|c|c|c|}
\hline \multirow{2}{*}{ Tratamentos } & \multicolumn{9}{|c|}{ Médias } \\
\hline & INC $^{3}$ & $\mathrm{DN}^{3}$ & PDSEV $^{2}$ & $\mathrm{PDAFL}^{2}$ & $\mathrm{CLOR}^{2}$ & $\mathrm{PC}^{3}$ & $\mathrm{PT}^{3}$ & $\mathrm{~PB}^{3}$ & $\mathrm{RPC}^{3}$ \\
\hline $\mathrm{NCA} 6 \mathrm{CH}$ & $2,0^{\mathrm{NS}}$ & $5,1^{\mathrm{NS}}$ & $164,2^{\mathrm{NS}}$ & $879,4^{\mathrm{NS}}$ & $66,6^{\mathrm{NS}}$ & $34,4^{\mathrm{NS}}$ & $16,8^{\mathrm{NS}}$ & $67,1^{\mathrm{NS}}$ & $63,0^{\mathrm{NS}}$ \\
\hline $\mathrm{NCA} 12 \mathrm{CH}$ & 1,9 & 5,6 & 167,2 & 968,0 & 66,1 & 30,4 & 16,2 & 64,7 & 55,0 \\
\hline $\mathrm{NCA} 30 \mathrm{CH}$ & 1,9 & 5,1 & 166,2 & 943,5 & 65,0 & 32,0 & 15,9 & 63,7 & 63,4 \\
\hline Testemunha & 2,0 & 5,0 & 166,3 & 998,3 & 65,0 & 31,8 & 16,2 & 64,7 & 64,7 \\
\hline Média & 1,9 & 5,2 & 165,9 & 947,3 & 65,7 & 32,2 & 16,3 & 65,0 & 61,5 \\
\hline CV (\%) & 44,1 & 50,7 & 6,7 & 18,1 & 5,3 & 74,8 & 28,8 & 28,8 & 14,9 \\
\hline
\end{tabular}

NS, resultados não significativos a 5\% de probabilidade pelo teste de F. NCA, nitrato de cálcio. ${ }^{2} \mathrm{e}^{3}$, respectivamente 2 e 3 anos de avaliações.

A severidade de míldio, seja quantificada pela porcentagem de folhas danificadas em 2011/12 no experimento com sulfato de potássio, seja calculada pela AACPD no experimento com nitrato de cálcio em 2014/15, não diferiu entre tratamentos (Tabelas 1 e 2). O manejo do míldio com moléculas alternativas não tem demonstrado eficiência satisfatória, quando comparado aos fungicidas convencionais (WORDELL FILHO et al., 2007). A morfologia foliar da cebola associada à alta cerosidade são fatores que podem explicar a ineficiência da pulverização de diferentes produtos no controle da doença. Altas diluições de calcário de conchas $6 \mathrm{CH}$, Natrum muriaticum $12 \mathrm{CH}$, e sulfato de zinco 6, 12 e 30CH também não alteraram a severidade de míldio em cebola em sistema orgânico. 
O potássio em alta diluição, Kali $60 \mathrm{CH}$, também não influenciou a necrose foliar causada por pinta preta, Alternaria solani, e requeima, Phytophtora infestans, em batata (RAUBER et al., 2007).

Tabela 2. Notas da incidência (INC) e danos (DN) de Thrips tabaci por planta; severidade do míldio (Peronospora destructor) com porcentagem de área foliar lesionada (SEV); índice de clorofila (CLOR); porcentagem de bulbos comerciais (PC); produtividade total (PT em t.ha-1); peso médio de bulbos (PB em g); porcentagem de rendimento pós-colheita (RPC) de cebola. Epagri, Ituporanga, SC, média das safras 2011, 2012 e 2013.

\begin{tabular}{ccccccccc}
\hline \multirow{2}{*}{ Tratamentos } & \multicolumn{7}{c}{ Médias } \\
\cline { 2 - 9 } & INC & $\mathrm{DN}^{3}$ & $\mathrm{SEV}^{2}$ & $\mathrm{CLOR}^{2}$ & $\mathrm{PC}^{3}$ & $\mathrm{PT}^{3}$ & $\mathrm{~PB}^{3}$ & $\mathrm{RPC}^{3}$ \\
\hline NCA 6 CH & $3,5^{\mathrm{NS}}$ & $5,6^{\mathrm{NS}}$ & $29,0^{\mathrm{NS}}$ & $70,5^{\mathrm{NS}}$ & $32,1^{\mathrm{NS}}$ & $17,0^{\mathrm{NS}}$ & $68,1^{\mathrm{NS}}$ & $57,7^{\mathrm{NS}}$ \\
\hline NCA 12 CH & 3,6 & 5,6 & 29,8 & 72,1 & 30,0 & 16,9 & 67,7 & 56,3 \\
\hline NCA 30 CH & 3,6 & 4,9 & 29,9 & 70,9 & 31,5 & 17,2 & 68,7 & 56,3 \\
\hline Testemunha & 3,7 & 5,7 & 30,4 & 71,3 & 34,2 & 16,8 & 67,1 & 55,4 \\
\hline Média & 3,6 & 5,4 & 29,8 & 71,2 & 31,9 & 17,0 & 67,9 & 56,4 \\
\hline CV (\%) & 23,2 & 28,3 & 18,7 & 3,3 & 48,1 & 16,3 & 16,2 & 16,4 \\
\hline
\end{tabular}

$\mathrm{NS}$, resultados não significativos a $5 \%$ de probabilidade pelo teste de $\mathrm{F}$. SK, sulfato de potássio. ${ }^{2} \mathrm{e}^{3}$, respectivamente $2 \mathrm{e}$ 3 anos de avaliações.

O índice de clorofila foi em média 65,7 e 71,2, respectivamente para os experimentos de nitrato de cálcio e sulfato de potássio, e não diferiu entre tratamentos (Tabelas 1 e 2). A importância deste índice é verificar se não houve fitotoxidez ou alteração da atividade fotossintética das plantas. Portanto, os tratamentos não influenciaram estas variáveis. Os teores de clorofila de cebola em sistema orgânico também não foram alterados por altas diluições de calcário de conchas $6 \mathrm{CH}$, Natrum muriaticum 12CH, e sulfato de zinco 6, 12 e 30CH (GONÇALVES et al., 2014a,b).

A porcentagem de bulbos comerciais $(32,2 \%, 31,9 \%)$, a produtividade total $\left(16,3\right.$ t.ha $^{-1}, 17,0$ t.ha- $\left.{ }^{-1}\right)$, o peso de bulbos $(65,0 \mathrm{~g}, 67,9 \mathrm{~g})$, não diferiram entre tratamentos, respectivamente nos experimentos de nitrato de cálcio e sulfato de potássio (Tabelas 1 e 2). Isto contrasta com o efeito de substância composta por cálcio, como calcário de conchas e Calcarea fluorica em incrementar biomassa em aliáceas (LUIS \& MORENO, 2007; GONÇALVES et al., 2009). Os resultados também diferem do efeito negativo no desenvolvimento de plantas de coentro com substância em alta diluição composta por cálcio, Calcarea carbonica 6CH (NUNES, 2013). Similarmente substância composta por potássio, Kali $60 \mathrm{CH}$, também não incrementou a produtividade em batata (RAUBER et al., 2007).

O rendimento pós-colheita $(61,5 \%, 56,1 \%)$, respectivamente nos experimentos de nitrato de cálcio e sulfato de potássio também foi similar entre tratamentos (Tabelas 1 e 2). A conservação de frutos de tomateiro nas características físicas e químicas também não foi alterada quando utilizado Calcarea carbonica na 6 e 12 CH (MODOLON et al., 2012). O efeito similar dos tratamentos no rendimento na pós-colheita difere da redução nas perdas na conservação dos bulbos de cebola observada com a aplicação associada de Natrum muriaticum 12CH e Calcarea carbonica 6CH (GONÇALVES et al., 2014a). O uso de substância em alta diluição composta por potássio, Kali iodatum $30 \mathrm{CH}$, no controle do fungo causador da podridão pós-colheita em frutos do morango, Alternaria alternata, também foi não significativo (PATIL \& SURYAWANSHI, 2014). 


\section{CONCLUSÕES}

A incidência e danos de tripes, índice de clorofila, severidade de míldio, produtividade e rendimento pós-colheita não foram influenciados por altas diluições dinamizadas de nitrato de cálcio e sulfato de potássio.

\section{AGRADECIMENTOS}

A Fundação de Amparo à Pesquisa e Inovação do Estado de Santa Catarina, FAPESC, pelo apoio financeiro na execução dos experimentos.

\section{REFERÊNCIAS}

CARNEIRO, Solange Maria de Toledo Piza Gomes; OLIVEIRA, Bruno G.; FERREIRA, Isabella F. Efeito de medicamentos homeopáticos, isoterápicos e substâncias em altas diluições em plantas: revisão bibliográfica. Revista de Homeopatia, v.74, n.(1/2), p.9-32, 2011.

FARMACOPÉIA HOMEOPÁTICA BRASILEIRA. 3 ed. 2011. Disponível em: <http://www.anvisa.gov.br/hotsite/farmacopeiabrasileira/conteudo/3a_edicao.pdf.> Acesso em: 13 julho 2017.

GONÇALVES, Paulo Antonio de Souza. Manejo de pragas. In: MENEZES JÙNIOR, Francico Olmar Gervini; MARCUZZO, Leandro Luiz (org.) Manual de boas práticas agrícolas: Guia para a sustentabilidade das lavouras de cebola do estado de Santa Catarina. Florianópolis: Epagri, 2016. 143p. Cap. 8, p.81-90.

GONÇALVES, Paulo Antonio de Souza; BOFF, Pedro; BOFF, Mari Inês Carissimi. Influência do preparado homeopático de calcário de conchas sobre tripes e produtividade de cebola. Agropecuária Catarinense, v.22, n.1: p.91-93, 2009.

GONÇALVES, Paulo Antonio de Souza; BOFF, Pedro; BOFF, Mari Inês Carissimi. Preparado homeopático de losna, Artemisia vulgaris L., no manejo de tripes e seu efeito sobre a produção de cebola em sistema orgânico. Revista Brasileira de Agroecologia, v.5, n.2, p.16-21, 2010.

GONÇALVES, Paulo Antonio de Souza; BOFF, Pedro; BOFF, Mari Inês Carissimi; NESI, Cristiano Nunes. Efeito da aplicação do preparado homeopático de Natrum muriaticum na incidência de Thrips tabaci, na produtividade e na armazenagem de cebola em sistema orgânico. Agropecuária Catarinense, v.24,n.2: p.76-78, 2011.

GONÇALVES, Paulo Antonio de Souza; BOFF, Pedro; MENEZES JÚNIOR, Francisco Olmar Gervini de. Efeito de altas diluições de calcário de conchas e Natrum muriaticum no manejo fitossanitário, na produtividade e na armazenagem de cebola em sistema orgânico. Agropecuária Catarinense, v.27, n.3: p.78-82, 2014 .

GONÇALVES, Paulo Antonio de Souza; BOFF, Pedro; MENEZES JÚNIOR, Francisco Olmar Gervini de. Altas diluições de sulfato de zinco sobre o manejo de tripes e rendimento de cebola em sistema orgânico. Revista de Homeopatia, v.77, n.(1/2): p.10-15, 2014b.

GONÇALVES, Paulo Antonio de Souza; CARRÉ-MISSIO, Vivian. Efeito de substâncias ultradiluídas de sulfatos de zinco e cobre, nitrato de cálcio, trigo mourisco, sobre a incidência e dano de tripes, 
incidência e severidade de míldio, e rendimento de cebola em sistema orgânico. Cadernos de Agroecologia, v.6, n.2: p.10597, 2011.

GONÇALVES, Paulo Antonio de Souza; VIEIRA NETO, João; CARVALHO, Patrícia Gonçalves Baptista de. Efeito da pulverização foliar de preparados homeopáticos de Natrum muriaticum e calcário de conchas sobre a composição mineral de bulbos de cebola em sistema orgânico. Agropecuária Catarinense, v.25, n.3: p.80-84, 2012.

GONÇALVES, Paulo Antonio de Souza; WAMSER, Gerson Henrique. Produção orgânica de cebola com agricultores familiares. Revista Brasileira de Agroecologia. v.2, n.3: p.63-68, 2007;. Disponível em: http://www6.ufrgs.br/seeragroecologia/ojs/. Acesso em: 13 julho 2017.

IBGE. Sistema IBGE de recuperação automática - SIDRA. Previsão de safras. On line. Disponível em: <http://www.sidra.ibge.gov.br>. Acesso em: 18 jan. 2016.

LUIS, Sánchez Sánchez Jorge; MORENO, Niurka Meneses. Efecto de cinco medicamentos homeopaticos en la producción de peso fresco, en cebollín (Allium fistolosum). 2007. Disponível em <http://inforganic.com/node/1477>. Acesso em: 10 mar. 2016.

MENEZES JÚNIOR, Francisco Olmar Gervini de; GONÇALVES, Paulo Antonio de Souza; KURTZ, Claudinei. Biomassa e extração de nutrientes da cebola sob adubação orgânica e biofertilizantes. Horticultura Brasileira, v.31, n.4: p.642-648, 2013.

MARCUZZO, Leandro Luiz; ARAúJO, Edivânio Rodrigues. Manejo de doenças. In: MENEZES JÚNIOR, Francisco Olmar Gervini; MARCUZZO, Leandro Luiz (org.) Manual de boas práticas agrícolas: Guia para a sustentabilidade das lavouras de cebola do estado de Santa Catarina. Florianópolis: Epagri, 2016. 143p. Cap. 9, p.91-111.

MINISTÉRIO DA AGRICULTURA E DO ABASTECIMENTO. Instrução Normativa n. 46 de 06
de outubro de $2011 . \quad$ Anexo <http://www.agricultura.gov.br/arq_editor/file/Desenvolvimento_Sustentavel/Organicos/Legislacao/ Nacional/Instrucao_Normativa_n_0_046_de_06-10-2011.pdf>. Acesso em: 06 mai. 2016.

MODOLON, Tatiani Alano; BOFF, Pedro; ROSA, Joatan Machado; SOUSA, Paulina Mariele R.; MIQUELLUTI, David José. Qualidade pós-colheita de frutos de tomateiro submetidos a preparados em altas diluições. Horticultura Brasileira, v.30, n.1: p.58-63, 2012.

MOHIBULLAH. Studies on major diseases of bulb vegetables (onion and garlic) in N.W.F. P. (Pakistan). Tarnab (Peshswar) Pakistan: Final Technical Report, Agricultural Research Institute. 1992. 130p.

NUNES, Flávia de Jesus. Observação da influência de Calcarea carbonica na dinamização 6CH sobre o crescimento e desenvolvimento do coentro (Coriandrum sativum L.) cultivar "Verdão". Cadernos de Agroecologia, v.8, n.2: 13480, 2013.

PATIL, J.S.; SURYAWANSHI, N.S. Fruit rot of strawberry caused by Alternaria alternata control using homoeopathic medicines. International Journal of Pharmaceutical Science Invention, v.3, n.2: p.57-58, 2014.

PÔRTO, Diego Resende de Queirós; CECÍLIO FILHO, Arthur Bernardes; MAY, André; VARGAS, Pablo Forlan. Acúmulo de macronutrientes pela cultivar de cebola "Superex" estabelecida por semeadura 
direta. Ciência Rural, Santa Maria, v.37, n.4, p.949-955, 2007. Disponível em: <http://www.scielo.br/pdf/cr/v37n4/a05v37n4>. Acesso em: 09 mai. 2016.

RAUBER, Luiz Paulo; BOFF, Mari Inês Carissimi; SILVA, Zilmar; FERREIRA Antonio; BOFF, Pedro. Manejo de doenças e pragas da batateira pelo uso de preparados homeopáticos e variabilidade genética. Revista Brasileira de Agroecologia, v.2, n.2: p. 1008-1011, 2007.

SHANER, Gregory; FINNEY, Robert E. The effect of nitrogen fertilization on the expression of slowmildewing resistance in Knox wheat. Phytopathology, v.67, n.8: p. 1051-1056, 1977.

TICHAVSKÝ, Radko. Homeopatía para las plantas. Monterrey, Nuevo Leon: Fujimoto, Centro Universitario Comenius, 2009.

VIDIGAL, Sanzio Mollica; MOREIRA, Marialva Alvarenga; PEREIRA, Paulo Roberto Gomes. Crescimento e absorção de nutrientes pela planta cebola cultivada no verão por semeadura direta e por transplantio de mudas. Bioscience Journal, Uberlândia, v.26, n.1, p.59-70, 2010. Disponível em: <http://www.seer.ufu.br/index.php/biosciencejournal/article/viewArticle/7036>. Acesso em: 09 maio 2016.

WORDELL, FILHO João Américo; MARTINS, Daniel A.; STADNIK, Marciel J. Aplicação foliar de tratamentos para o controle do míldio e da podridão-de-escamas de bulbos de cebola. Horticultura Brasileira, v.25, n.4: p.544-549, 2007. 